\title{
Ectopic expression of CNN2 of colon cancer promotes cell migration
}

\author{
Lei Zheng ${ }^{1}$, Peng Zhao $^{1}$, Kai Liu ${ }^{1}$, Da-Lu Kong ${ }^{2}$ \\ ${ }^{1}$ Department of Colorectal Cancer, Tianjin Medical University Cancer Institute and Hospital, National Clinical Research Center for Cancer, Key \\ Laboratory of Cancer Prevention and Therapy, Tianjin, Tianjin's Clinical Research Center for Cancer, Tianjin 300060, China; ${ }^{2}$ Department of \\ Colorectal Cancer, Tianjin Medical University Cancer Institute and Hospital, Tianjin 300060, China \\ Contributions: (I) Conception and design: L Zheng; (II) Administrative support: DL Kong; (III) Provision of study materials or patients: L Zheng, \\ P Zhao; (IV) Collection and assembly of data: L Zheng; (V) Data analysis and interpretation: L Zheng; (VI) Manuscript writing: All authors; (VII) \\ Final approval of manuscript: All authors. \\ Correspondence to: Dr. Da-Lu Kong. Department of Colorectal Cancer, Tianjin Medical University Cancer Institute and Hospital, Tiyuanbei, Hexi, \\ Tianjin 300060, China. Email: dalukongcnn2@sina.com.
}

Background: Calponin is an actin filament-associated regulatory protein originally identified in smooth muscle cells. Three homologous have been identified in vertebrate species, but little functional characterization of potential activities in cancer has been performed. In this study, we determined the levels of CNN2 in colon cancer cell lines and determined the effects of this protein by increasing expression.

Methods: We used IHC and RT-PCR to measure CNN2 expression in colon cancer tissues and normal tissues and found increased expression levels in cancer tissues. We used viral vectors to decrease the level of CNN2 in the SW480 colon cancer cell line and found that silencing of CNN2 inhibited cell invasion. We detected potential protein interactions in signal pathways by western bolt analysis. To confirm the effect of CNN2 on cell invasion, we increased CNN2 expression in the SW620 cell line and observed increased invasion increased expression levels of associated proteins.

Results: High-expression levels of CNN2 were detected in cancer tissues. Silencing CNN2 inhibited cell invasion, down-regulated N-cadherin (N-CA) and C-myc proteins, and up-regulated E-cadherin (E-CA), suggesting that CNN2 promotes colon cancer cell invasion. Increasing CNN2 levels in the SW620 cell line showed the opposite results.

Conclusions: CNN2 may act to promote colon cancer.

Keywords: CNN2; invasion; colorectal cancer

Submitted Jul 02, 2019. Accepted for publication Nov 29, 2019.

doi: $10.21037 /$ tcr.2019.12.61

View this article at: http://dx.doi.org/10.21037/tcr.2019.12.61

\section{Introduction}

After lung cancer, colorectal cancer is the second most deadly malignancy, with 135,430 deaths from this disease in 2017, although it is only the fourth most commonly diagnosed cancer in the U.S. $(1,2)$. In Taiwan, colorectal cancer is the most common diagnosed cancer. Mortality rates in Taiwan have increased rapidly, with an age-standardized incidence rate of 34.0 per 100,000 in the year of 2002 and 43.0 in 2015 (3). There have been limited studies of diagnosis and treatment of colorectal cancer, and most deaths of patients with colorectal cancers result from distant metastasis.

Calponin is a widely distributed actin-binding protein that acts in smooth-muscle contraction. Calponin also functions in cell signal transduction and maintaining the cytoskeleton (4). Three homologous genes are present in vertebrate species, CNN1, CNN2, and CNN3, which encode calponin isoforms 1, 2, and 3, respectively. Downregulation of $\mathrm{CNN} 2$ inhibited hepatocarcinoma (5) and suppressed cell growth in gastric cancer cells (6). However, 
loss of CNN2 induced migration of prostate cancer cells (7). To obtain further insight into the activity of calponin during cancer, we examined the levels of $\mathrm{CNN} 2$ in colon cancer.

\section{Methods}

\section{Cancer tissue and cell lines}

We selected 50 paired tissues from the Tianjin Cancer Hospital obtained between June, 2017 and June, 2018, and stored the samples at $-80^{\circ} \mathrm{C}$. The patients had not received chemotherapy before surgeries. Cell lines were obtained from the Shanghai Cell Bank, and included HCT-116, SW480, SW620, and HT29.

\section{Transfection}

CNN2 shRNA sequence (ACAGAAAAACCCAAAAACCCA $\left(5^{\prime} \rightarrow 3^{\prime}\right)$ and its complementary antisense strand GGUUUUUGGGUUUUUCUGUGU $\left(5^{\prime} \rightarrow 3^{\prime}\right)$ was purchased from Jikai (Shanghai, China), and found to efficiently reduce CNN2 in cancer cell lines. The control group contained shCtrl. The expression plasmid was bought from Origene, and was designated PC-CCN2, and the control vector was designated PCMV6.

\section{RT-PCR}

TRIzol reagent (Takara Bio, Shiga, Japan) was used to isolate total RNA from frozen cancer tissues. Basically, $1 \mathrm{~mL}$ TRIzol reagent and $300 \mu \mathrm{L}$ chloroform were added to the tissues and then centrifuged for $15 \mathrm{~min}$ at $10,000 \mathrm{rpm}$. Next, the same volume of isopropanol was added to the supernatant, and the samples were centrifuged again for $10,000 \mathrm{rpm}$ for $15 \mathrm{~min}$. The supernatant was discarded and $1 \mathrm{~mL}$ of $75 \%$ ethanol was added to wash the pellet. Next, the extracted RNA was reverse transcribed using a kit according to the manufacturer's instructions (Takara). We then designed amplification primers for the messenger RNA (mRNA) based on the specific DNA sequences of interest (Shanghai, China). The expression of mature CNN2 was measured using a Thermal Cycler Dice Real Time System II with the following thermocycling conditions: $95^{\circ} \mathrm{C}$ for $30 \mathrm{~s}, 45$ cycles of $95^{\circ} \mathrm{C}$ for $5 \mathrm{~s}$, and $60{ }^{\circ} \mathrm{C}$ for $60 \mathrm{~s}$, followed by melt-curve analysis. The relative expression of CNN2 was normalized to the expression of glyceraldehyde3phosphate dehydrogenase mRNA, and the fold change in expression was calculated using the $2^{-\Delta \Delta \mathrm{Ct}}$ method. We defined the negative value as relatively low expression level of CNN2 mRNA and a positive value as a relatively high expression level of CNN2 mRNA for cancer tissue compared with adjacent non-tumor tissue.

\section{Western blot}

RIPA was used to disrupt cells and obtain proteins from cell lines. A microplate reader was used to measure protein concentration. Samples were heated at a temperature of $95^{\circ} \mathrm{C}$ for $5 \mathrm{~min}$, mixed with loading solution, separated by sodium dodecyl sulfate polyacrylamide gel electrophoresis using $10 \%$ gels, isolated, and transferred to polyvinylidene difluoride membranes (Millipore, Billerica, MA). Membranes were incubated in nonfat milk powder for $2 \mathrm{~h}$. The protein was detected with a specific primary antibody [antibodies against CNN2, E-cadherin (E-CA), N-cadherin (N-CA), C-MYC, and GAPDH, 1:1,000 dilutions, purchased from Abcam] and a corresponding secondary antibody.

\section{Cell invasion}

After silencing CNN2 in the SW480 cell line, we incubated cells in the upper chamber at a concentration of 20,000/ well, and then added $600 \mu \mathrm{L}$ solution of RPMI-1640 with $10 \%$ FBS for $24 \mathrm{~h}$ without Matrigel, pore size of $0.4 \mu \mathrm{m}$. Cold methanol was used to freeze cells stuck on the bottom of the upper chamber. Staining with hematoxylin was performed to determine the number of cells passing through the chamber.

\section{Statistical analysis}

Differences in mRNA expression were analyzed using unpaired t-tests, and the relationship between clinical data and CNN2 protein expression levels were analyzed using $\chi^{2}$ tests. All other statistical analyses were performed using paired t tests. Results with p values of less than 0.05 were considered significant. All data analyses were performed using SPSS 17.0.

\section{Results}

\section{CNN2 is bighly expressed in colon cancer tissues}

We used RT-PCR to test 40 paired normal tissues and cancer tissues from patients in an existing tissue collection and found higher expression of CNN2 in cancer tissues 

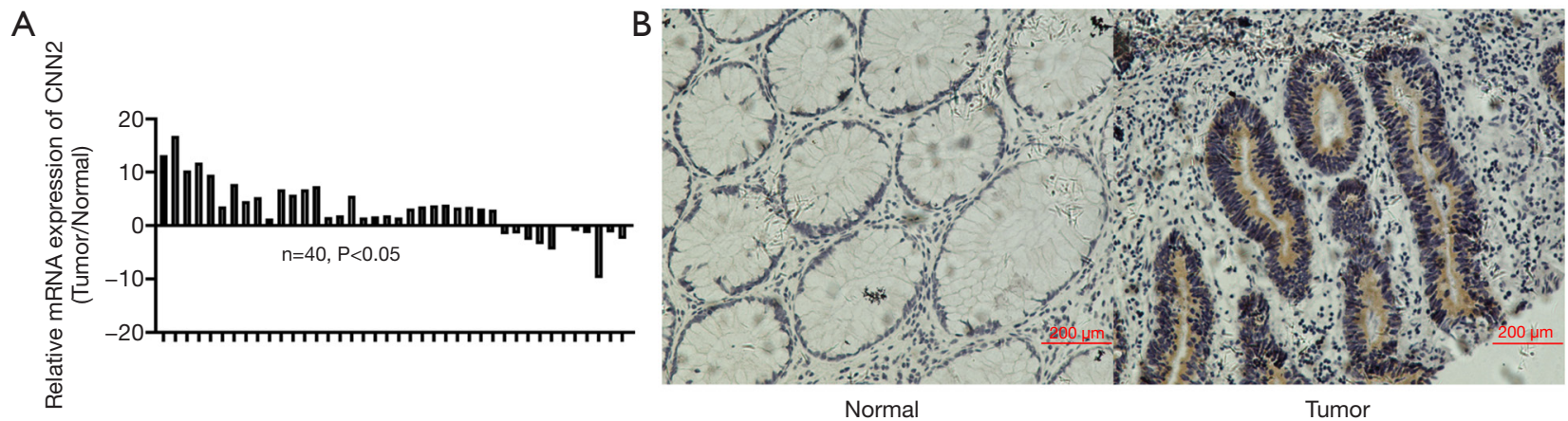

C
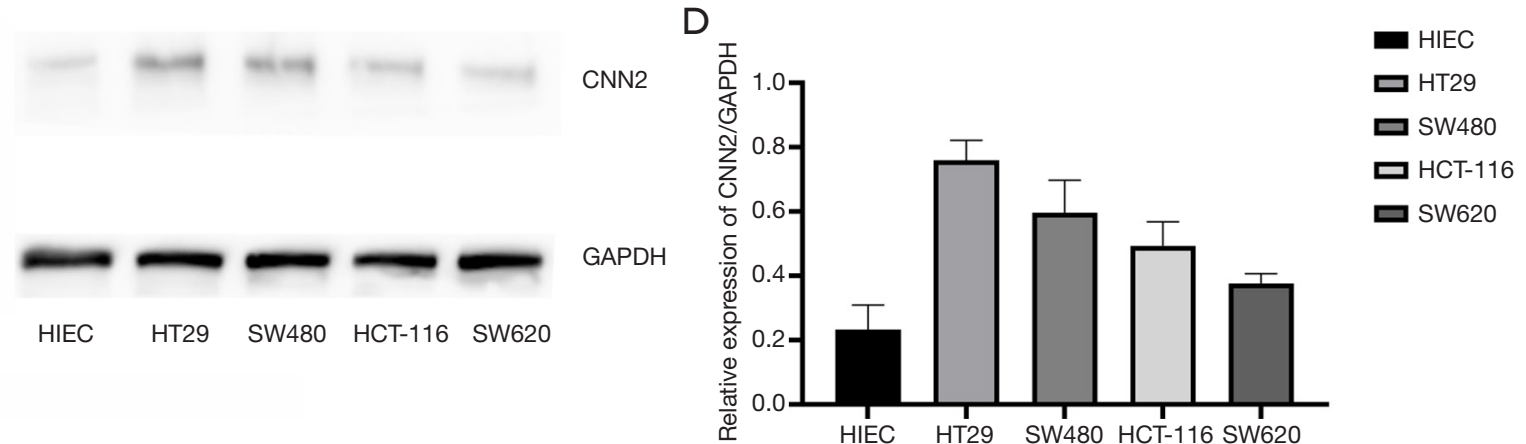

Figure 1 Expression levels of CNN2. (A) CNN2 mRNA levels in cancer tissues com and paired normal tissues (n=40); (B) normal tissues harbor low expression of CNN2 and cancer tissues show high expression of CNN2 by IHC (scale bar =200 $\mu \mathrm{m}$ ); (C) levels of CNN2 in five cell lines; (D) data analysis.

compared to paired normal tissues (Figure $1 A, \mathrm{P}<0.05$ ). To expand the number of samples, we next collected 50 additional sets of paired tissues (normal tissues and cancer tissues) from patients who underwent cancer surgery in the hospital between June, 2017 and June, 2018. Measurements of CNN2 protein levels in these new samples similarly revealed higher levels of $\mathrm{CNN} 2$ in the cancer tissues (Figure 1B). We next examined the CNN2 levels in four cancer cell lines and found the highest level in SW480 and the lowest value in SW620 (Figure 1C). We also measured the CNN2 protein level in HIEC, a human normal colon tissue, and we found lower CNN2 protein levels compared to the levels in the cancer cell lines. Cell lines SW480 and SW620 were selected to further investigate the potential regulation by $\mathrm{CNN} 2$ of colon cancer in vitro.

\section{CNN2 has positive-association with M stage of colon cancer}

Based on independent scoring of two pathology professors, we divided 50 cases of intestinal cancer tissue into two groups of different CNN2 expression levels, and analyzed the corresponding clinical data. We found no association of
CNN2 expression levels with age, gender, tumor (T) stage, if the cancer had spread to nearby nymph nodes ( $\mathrm{N}$ stage), and differentiation, but higher expression of CNN2 was positively associated with the spread (metastasis) to distant sites ( $M$ stage; $P=0.014 ;$ Table 1 ). This result suggests that $\mathrm{CNN} 2$ may be related to migration mechanism in colon cancer cell lines.

\section{Viral vector can effectively alter the expression level of CNN2 in SW480 and SW620}

We used a viral vector to knock-down the expression levels of CNN2 in the SW480 cell line and a separate plasmid to up-regulate CNN2 in the SW620 cell line. After culturing for almost 1 week, we tested the ability of these vectors to alter the expression level of CNN2 and found the expected changes in the RNA and protein levels (Figure 2).

\section{Down-regulated expression of CNN2 of SW480 inbibits cell migration}

We transferred the same amount of cells of two groups in 
Table 1 Association of expression levels of $\mathrm{CNN}$ and clinical data

\begin{tabular}{|c|c|c|c|}
\hline \multirow{2}{*}{ Parameter } & \multicolumn{2}{|c|}{ CNN2 } & \multirow{2}{*}{$P$ value } \\
\hline & Low & High & \\
\hline Age (years) & & & 0.617 \\
\hline$<65$ & 5 & 10 & \\
\hline$\geq 65$ & 16 & 19 & \\
\hline Gender & & & 0.443 \\
\hline Male & 7 & 14 & \\
\hline Female & 14 & 15 & \\
\hline T stage & & & 0.133 \\
\hline 1 & 6 & 3 & \\
\hline 2 & 5 & 7 & \\
\hline 3 & 7 & 7 & \\
\hline 4 & 3 & 12 & \\
\hline $\mathrm{N}$ stage & & & 0.185 \\
\hline 0 & 9 & 7 & \\
\hline 1 & 9 & 12 & \\
\hline 2 & 3 & 10 & \\
\hline M stage & & & 0.014 \\
\hline 0 & 14 & 8 & \\
\hline 1 & 7 & 21 & \\
\hline Differentiation & & & 0.788 \\
\hline Poor & 5 & 6 & \\
\hline Medium & 6 & 11 & \\
\hline Well & 10 & 12 & \\
\hline Tumor location & & & 0.218 \\
\hline Right colon & 10 & 7 & \\
\hline Left colon & 5 & 11 & \\
\hline Rectal colon & 6 & 11 & \\
\hline Tumor size (cm) & & & 0.315 \\
\hline$<5$ & 7 & 15 & \\
\hline$\geq 5$ & 14 & 14 & \\
\hline
\end{tabular}

chambers (up) in RPMI-1640 with $10 \%$ FBS. After 24 h of cultivation, we found that silencing CNN2 inhibited cell migration of the SW480 cells. In the SW620 cell line, upregulation of $\mathrm{CNN} 2$ promoted (Figure 3).

\section{Silencing CNN2 inbibits cell migration by targeting the C-myc signal pathway}

After decreasing CNN2 in the SW480 cell line, we tested the levels of several proteins with functions associated with migration. C-myc and N-CA exhibited decreased expression levels with decreased CNN2, and the level of E-CA was increased in this condition. These results indicated that CNN2 may promote cell migration by targeting the C-myc signal pathway. We also measured the levels of these three proteins in the SW620 cell line with increased CNN2, and observed the opposite effects (Figure 4).

\section{Discussion}

Calponin is an actin filament-associated regulatory protein originally identified in smooth muscle cells. Three homologous genes are present in vertebrate species, $\mathrm{CNN} 1$, $\mathrm{CNN} 2$, and $\mathrm{CNN} 3$, which encode calponin isoforms 1 , 2 , and 3 , respectively $(8,9)$. In this study, we focused on isoform 2, which was previously studied in some other cancer tissues. We observed that CNN2 expression was higher in colon cancer cells than in paired normal tissues, as reported for other cancers $(5,6)$. After analyzing the data of patients with colon cancer, we found a positive association of $\mathrm{CNN} 2$ expression with $M$ stage, which may indicate that $\mathrm{CNN} 2$ may regulate cell migration. As reported previously, $\mathrm{H} 2$-calponin mRNA has been detected in endothelial cells and fibroblasts, suggesting that CNN2 regulates migration by regulating myofilament $(10,11)$.

We silenced CNN2 in the SW480 cell line, and tested cell migration ability. The results showed that CNN2 promotes the cell migration of colon cancer cells in vitro. E-CA is a well-known marker of the epithelialmesenchymal transition (EMT) required for the initiation of cell migration (12-14). We observed decreased levels of E-CA and N-CA with decreased CNN2 levels, as reported previously (15-17). The C-myc oncoprotein is overexpressed in a significant proportion of human epithelial cancers, and experimental overexpression of c-Myc in epithelial cells promotes tumour formation. The C-myc signal pathway is associated with E-CA (18), with cancer invasion in breast cancer (19), and C-myc and N-CA are also associate in lung cancer (20). In this study, we measured $\mathrm{C}$-myc protein expression and we found that decreased CNN2 levels correlated with decreased C-myc levels. The results suggest a potential relationship of EMT signal 

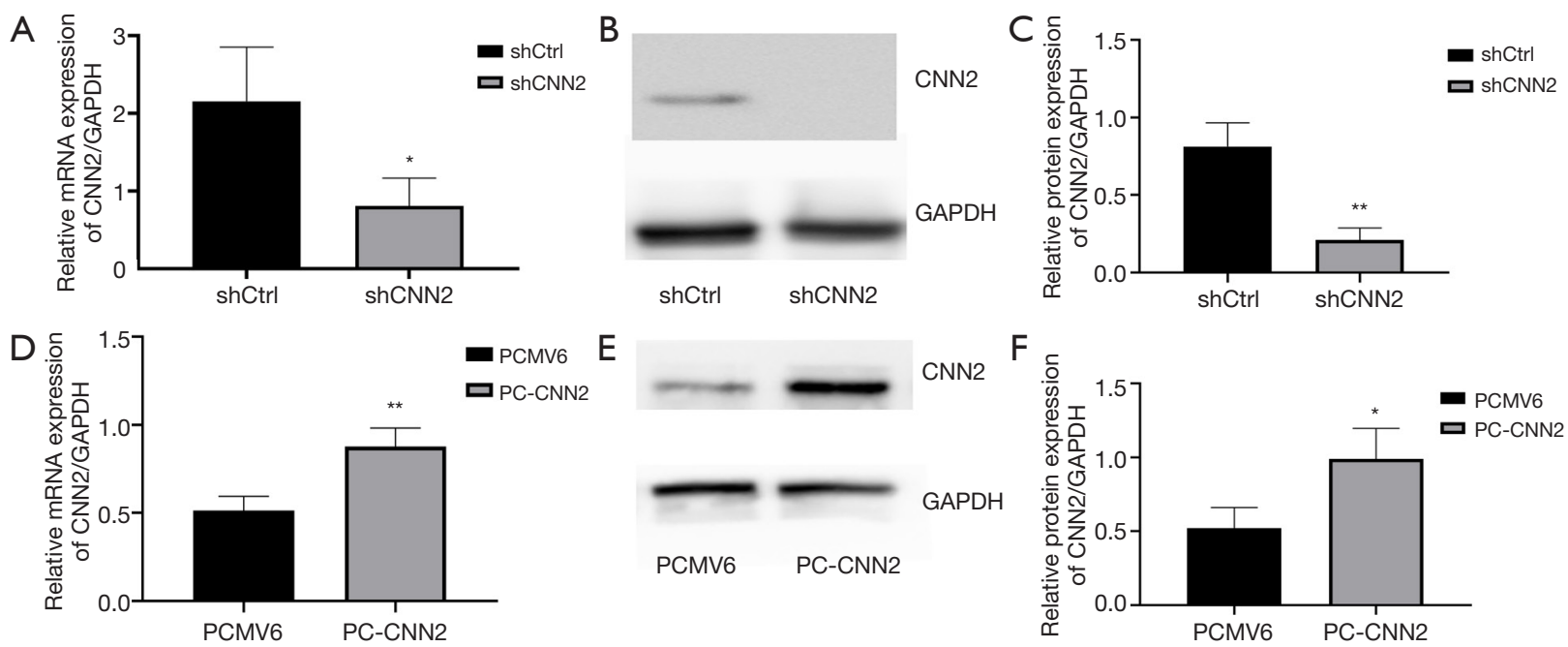

Figure 2 Altering CNN2 expression in SW480 and SW620 cell lines. (A,D) mRNA expression levels of CNN2 in SW480 cell lines after silencing or in SW620 after up-regulating; (B,E) protein expression levels of CNN2 after silencing or after up-regulating; (C,F) data analysis. Bars indicate \pm standard errors. *, $\mathrm{P}<0.05$; **, $\mathrm{P}<0.01$ compared with the control.

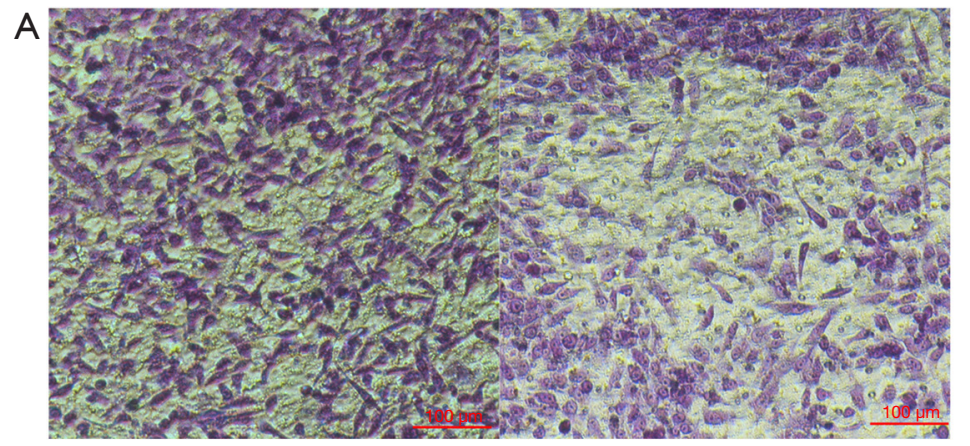

shCtrl

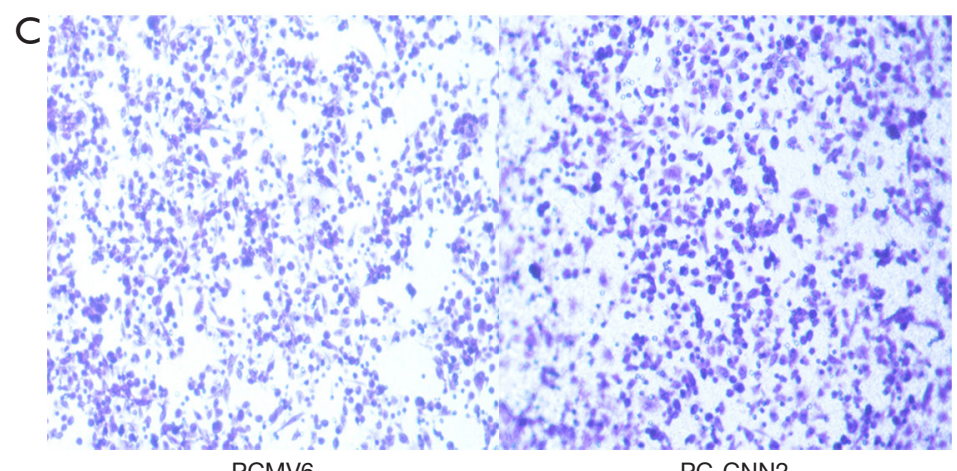

B
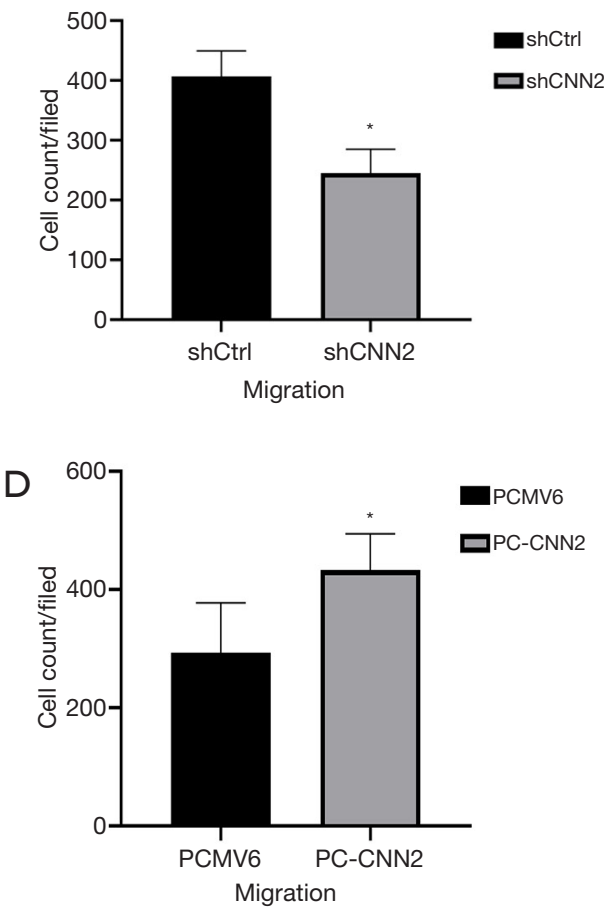

Figure 3 Cell invasion of SW480 cell line after silencing. (A,C) Cell invasion of SW480 and SW620 (Scale bar =100 $\mu$ m); (B,D) data analysis. Bars indicate \pm standard errors. ${ }^{*}, \mathrm{P}<0.05 ;{ }^{* *}, \mathrm{P}<0.01$ compared with the control. 

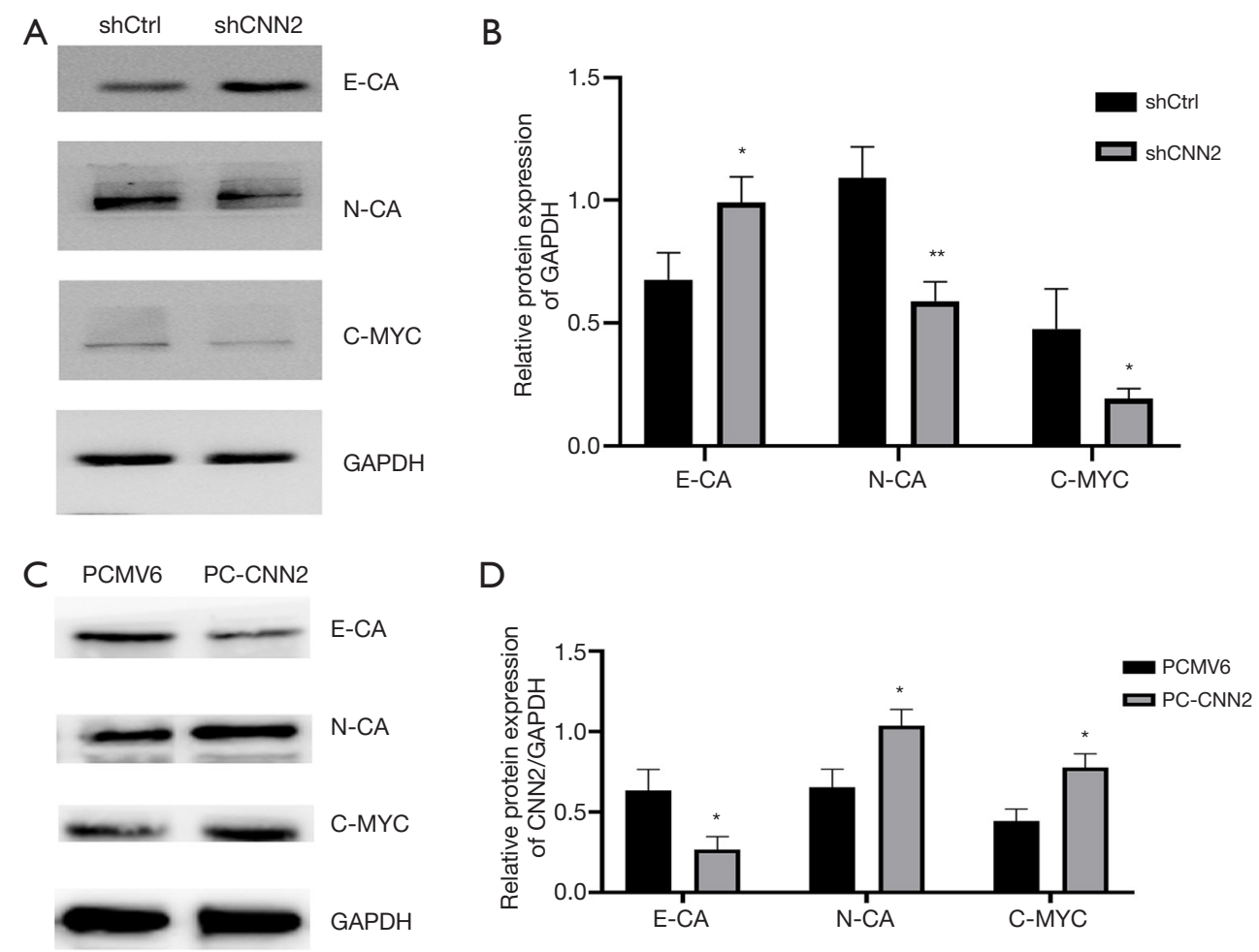

Figure 4 Downstream proteins are regulated by silencing CNN2. (A,C) N-CA and C-myc are down-regulated by silencing of CNN2, while E-CA is increased by silencing of CNN2; with increased CNN2, the opposite results were observed; (B,D) data analysis. Bars indicate \pm standard errors. * $\mathrm{P}<0.05$; **, $\mathrm{P}<0.01$ compared with the control.

pathways and CNN2.

The results indicated there are high levels of CNN2 in colon cancer tissues and this increased level has a positive association with $M$ stage. Overall, the results suggest that CNN2 promotes cell migration in colon cancer.

\section{Acknowledgments}

Funding: None.

\section{Footnote}

Conflicts of Interest: All authors have completed the ICMJE uniform disclosure form (available at http://dx.doi. org/10.21037/tcr.2019.12.61). The authors have no conflicts of interest to declare.

Ethical Statement: The authors are accountable for all aspects of the work in ensuring that questions related to the accuracy or integrity of any part of the work are appropriately investigated and resolved. The study was conducted in accordance with the Declaration of Helsinki (as revised in 2013). The Ethics Committee of China Medical University approved the research project and analysis of the patient specimens. ID/number of ethical approval: TJZL2018-00156. Informed consent was waived due to the nature of the study.

Open Access Statement: This is an Open Access article distributed in accordance with the Creative Commons Attribution-NonCommercial-NoDerivs 4.0 International License (CC BY-NC-ND 4.0), which permits the noncommercial replication and distribution of the article with the strict proviso that no changes or edits are made and the original work is properly cited (including links to both the formal publication through the relevant DOI and the license). See: https://creativecommons.org/licenses/by-nc$\mathrm{nd} / 4.0 /$.

\section{References}

1. National Cancer Institute Surveillance, Epidemiology, and 
End Results Program. Cancer stat facts: colon and rectum cancer. Available online: http://seer.cancer.gov/statfacts/ html/colorect.html. Accessed April 17, 2017.

2. American Cancer Society. Colorectal cancer facts \& figures. Available online: https://www.cancer.org/research/ cancer-facts-statistics/colorectal-cancer-facts-figures.html. Accessed April 17, 2017.

3. The Epidemiology of Colorectal Cancer in Taiwan. Health Promotion Administration, Ministry of Health and Welfare in Taiwan. Available online: https://www.hpa.gov. tw/Pages/Detail.aspx? nodeid=615\&pid=1126

4. Morgan KG, Gangopadhyay SS. Invited review: crossbridge regulation by thin filament-associated proteins. J Appl Physiol (1985) 2001;91:953-62.

5. Kang X, Wang F, Lan X, et al. Lentivirus-mediated shRNA Targeting CNN2 Inhibits Hepatocarcinoma in Vitro and in Vivo. Int J Med Sci 2018;15:69-76.

6. Hu J, Xie W, Shang L, et al. Knockdown of calponin 2 suppressed cell growth in gastric cancer cells. Tumour Biol 2017;39:1010428317706455.

7. Verone AR, Duncan K, Godoy A, et al. Androgenresponsive Serum Response Factor target genes regulate prostate cancer cell migration. Carcinogenesis 2013;34:1737-46.

8. Takahashi K, Hiwada K, Kokubu T. Isolation and characterization of a 34,000-dalton calmodulin- and F-actin-binding protein from chicken gizzard smooth muscle. Biochem Biophys Res Commun 1986;141:20-6.

9. Jin JP, Zhang Z, Bautista JA. Isoform diversity, regulation, and functional adaptation of troponin and calponin. Crit Rev Eukaryot Gene Expr 2008;18:93-124.

10. Sakihara C, Nishimura J, Kobayashi S, et al. Expression of calponin mRNA in porcine aortic endothelial cells. Biochem Biophys Res Commun 1996;222:195-200.

11. Masuda H, Tanaka K, Takagi M, et al. Molecular cloning and characterization of human non-smooth muscle

Cite this article as: Zheng L, Zhao P, Liu K, Kong DL. Ectopic expression of CNN2 of colon cancer promotes cell migration. Transl Cancer Res 2020;9(2):1063-1069. doi: 10.21037/tcr.2019.12.61 calponin. J Biochem 1996;120:415-24.

12. Zhang H, Luo H, Jiang Z, et al. Fractionated irradiationinduced EMT-like phenotype conferred radioresistance in esophageal squamous cell carcinoma. J Radiat Res 2016;57:370-80.

13. Ke K, Sun Z, Wang Z. Downregulation of long noncoding RNA GAS5 promotes cell proliferation, migration and invasion in esophageal squamous cell carcinoma. Oncol Lett 2018;16:1801-8.

14. Liu Y, Li Y, Wang R, et al. MiR-130a-3p regulates cell migration and invasion via inhibition of Smad4 in gemcitabine resistant hepatoma cells. J Exp Clin Cancer Res 2016;35:19.

15. Li LC, Peng Y, Liu YM, et al. Gastric cancer cell growth and epithelial-mesenchymal transition are inhibited by $\gamma$-secretase inhibitor DAPT. Oncol Lett 2014;7:2160-4.

16. Song Q, Xu Y, Yang C, et al. miR-483-5p Promotes Invasion and Metastasis of Lung Adenocarcinoma by Targeting RhoGDI1 and ALCAM. Cancer Res 2014;74:3031-42.

17. Bastea LI, Döppler H, Balogun B, et al. Protein Kinase D1 Maintains the Epithelial Phenotype by Inducing a DNA-Bound, Inactive SNAI1 Transcriptional Repressor Complex. PLoS One 2012;7:e30459.

18. Cowling VH, Cole MD. E-cadherin repression contributes to c-Myc-induced epithelial cell transformation. Oncogene 2007;26:3582-6.

19. Wang O, Yang F, Liu Y, et al. C-MYC-induced upregulation of lncRNA SNHG12 regulates cell proliferation, apoptosis and migration in triple-negative breast cancer. Am J Transl Res 2017;9:533-45.

20. Yang S, Liu Y, Li MY, et al. FOXP3 promotes tumor growth and metastasis by activating $\mathrm{Wnt} / \beta$-catenin signaling pathway and EMT in non-small cell lung cancer. Mol Cancer 2017;16:124. 